\title{
Investigation on Two-Phase Flow Characteristics in Nuclear Power Equipment
}

\author{
Lu Guangyao, Ren Junsheng, Huang Wenyou, Xiang Wenyuan, \\ Zhang Chengang and Lv Yonghong \\ China Guangdong Nuclear Power Holding Co. Ltd.
}

China

\section{Introduction}

Two-phase flow exits in many nuclear power equipments, such as containment sump strainer, steam generator, steam turbine, control rod drive mechanism and so on. Experimental investigations are carried out to study the two-phase flow patterns and their transitions in these nuclear power equipments. And the results show that the two-phase flow patterns and their transitions are quite different from those in normal circular tubes.

For tube-bundle channel heat transfer enhancement technique, it has great advantages in high heat transfer efficiency and compact configuration without complex machining or additional surface processing, which has been successfully used in steam generator in nuclear power station and other industrial equipments. The characteristics of boiling flow and heat transfer have an important impact on these industrial equipments. It was found that heat transfer characteristics of fluid flowing in tube-bundle channels were different from those in circular tubes on account of the special geometric frame and different flow patterns in tube-bundle channels (Petigrew \& Taylor, 1994). Boiling flow and heat transfer is a complex issue of twophase flow, and many studies have been conducted in this research area.

Experiments of boiling flow in tube-bundle channels were carried out in order to simulate boiling flow and heat transfer in fuel module of nuclear reactor (Bergles, 1981). The experimental results showed that there were many different aspects of flow patterns and their transitions in tube-bundle channels. Grant \& Chisolm (1979) and Ma (1992) made studies of air-water two-phase flow in tube-bundle heat exchangers, in which the vertical flow and horizontal flow experiments were conducted respectively. Grant \& Chisolm (1979) found that there were mist flow, bubbly flow, intermittent flow, stratified-mist flow and stratified flow in tub-bundle channels. But Ma (1992) detected stratified flow and wave flow in horizontal channels, and bubbly flow and intermittent flow in vertical channels, which was different from the results gained by Grant \& Chisolm (1979). Chan \& Shoukri (1987) conducted visualization experiments of refrigerant-113 flowing in tube-bundle channels, of which the tubes were arranged $1 \times 1,3 \times 1,3 \times 3$, and $9 \times 3$ respectively. Sadatomi \& Kawahara (2004) carried out experiments in tube-bundle channels, of which the tubes were arranged $2 \times 3$. On the basis of experiments, Sadatomi protracted flow pattern maps.

On the basis of the results obtained before, studies are carried out to investigate the characteristics of refrigerant 113 flowing in a tube-bundle channel, of which the tubes are 
arranged $2 \times 2$. Furthermore, flow visualization experiments are carried out with high-speed camera. Through the comparison between the experimental results and other works, it is found flow regimes and their transitions in the tube-bundle channel are different from other normal circular tubes.

In the event of LOCA (Loss-of-Coolant Accident) or HELB (High Energy Line Break) within the containment of a light-water reactor (LWR), the primary safety concern regarding the long-term recirculation is that accident-generated debris and resident debris may be transported to the recirculation sump screens, which would result in adverse blockage effects and loss of the pumps net positive suction head (NPSH) of the emergency core cooling system (ECCS) and the containment spray system (CSS). The debris may starve the sump and the head loss of water flow through the containment sump strainers may be so large that it would exceed the available NPSH margin of pumps of ECCS and CSS systems. The pressure loss due to the accident-generated debris accumulated on the sump screens would be computed through the debris types and contents which are determined to be destroyed and transported. So the computational researches were carried out to investigate the characteristics of containment sump strainers by Lu et al. (2011a, 2011b, 2011c).

For control rod drive mechanism (CRDM) in nuclear power station, it works in high pressure and high temperature condition and single-phase water is adopted as the working liquid. But two-phase flow would come into being in the cold-state test and hot-state test. The high speed camera is also used in the CRDM visualization tests in cold-state to investigate the characteristics of two-phase flow.

\section{Experiments}

\subsection{Experiments of tube-bundle channels}

A schematic diagram of the experimental apparatus is given in Fig.1, which is adopted to study the boiling two-phase flow in tube-bundle channels. In the experiments, all measured

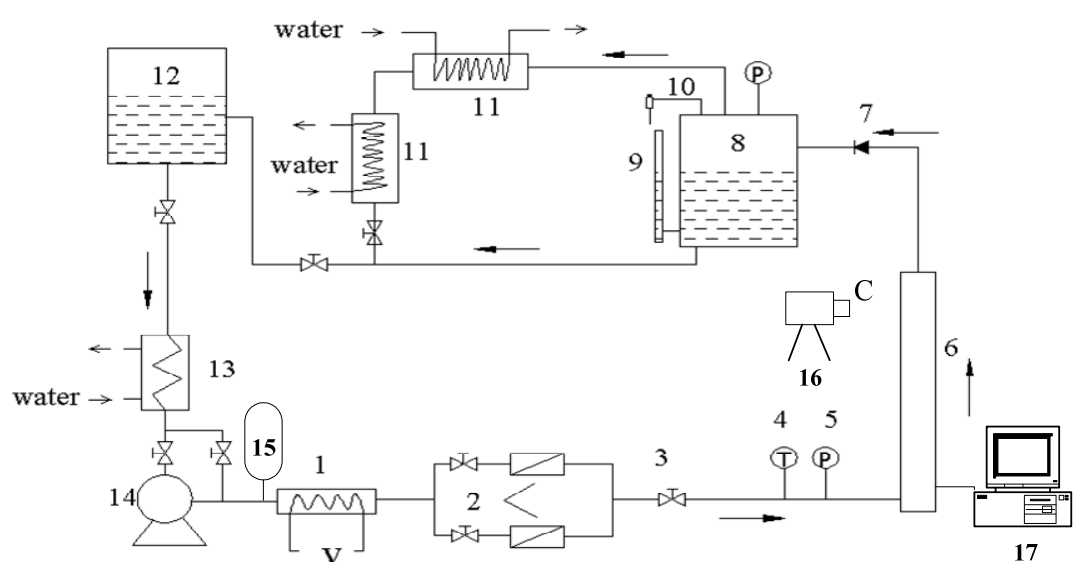

1. Preheater 2. Flowmeter 3. Control valve 4. Thermocouple 5. Pressure meter 6. Test section 7. Check valve 8. Seperator 9. Liquid-height meter 10. Relief valve 11. Condenser 12. Liquid tank 13. Cooler 14. Magnetopump 15. Manostat 16. High-speed camera 17. Data collector

Fig. 1. Schematic diagram of experimental apparatus (tube-bundle channel) 
data are recorded at the intervals of $10 \mathrm{~ms}$. The error in the pressure drop measurement is less than $\pm 2 \%$. The error in flow rate measurement is less than $\pm 3 \%$, and for temperature measurement is less than $\pm 1 \%$.

The test section of tube-bundle channel is composed of four straight electrical heaters and a thimble, which is shown in Fig. 2. The thimble is made of PMMA pipe for the purpose of flow visualization, of which the inner diameter is $35 \mathrm{~mm}$ and the length is $2100 \mathrm{~mm}$. The dimension of the electrical heater is $\Phi 8 \mathrm{~mm}$ and $1500 \mathrm{~mm}$ long; the gap between electrical heaters is $5 \mathrm{~mm}$; the width between electrical heater and thimble is $4.5 \mathrm{~mm}$. There are, along flow direction, three pressure sensors and five thermocouples. The length between pressure sensors is $200 \mathrm{~mm}$ and that between thermocouples is $100 \mathrm{~mm}$.

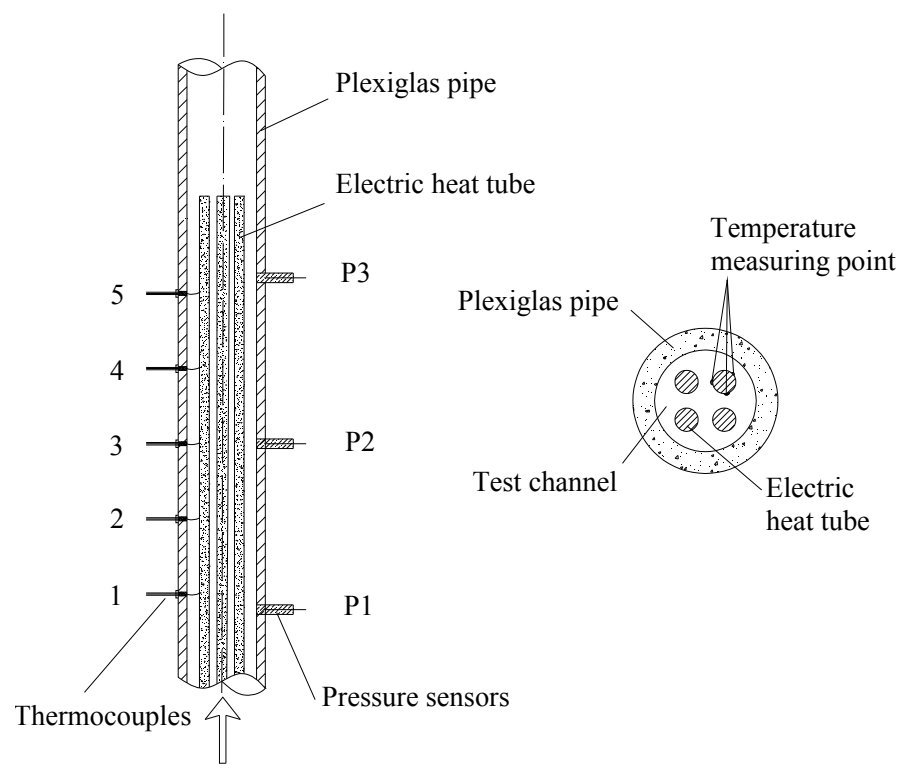

Fig. 2. Structure of test section

A schematic diagram of sub-channels partition is shown in Fig. 3. There are 9 sub-channels in the present test section.

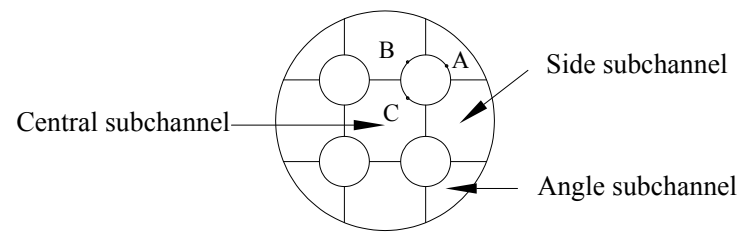

Fig. 3. Schematic diagram of sub-channels partition 


\subsection{Experiments of containment sump strainers}

For the tests of containment sump strainers, the schematic diagram of the experimental apparatus is given in Fig.4.

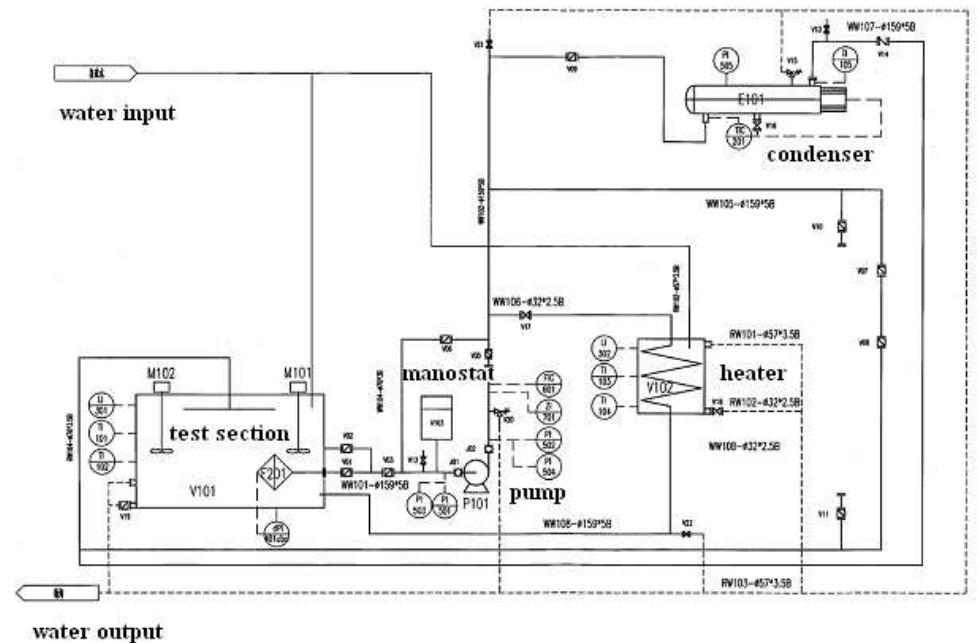

Fig. 4. Schematic diagram of experimental apparatus for containment sump strainers

In order to monitor the tests, the test apparatus includes flow rate measurements, temperature measurements, and differential pressure measurement. High speed camera is adopted to perform the visual observation of the two-phase flow and the debris bed during the test and after the test. The photos of the test system are shown in Figs 5 7.

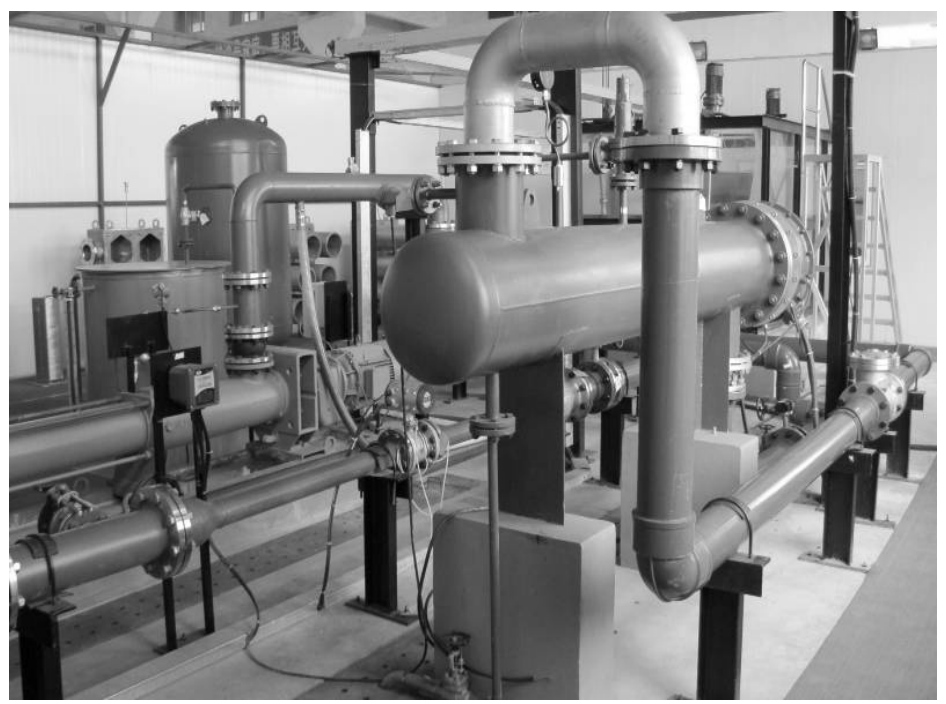

Fig. 5. Photograph 1 of the test system (containment sump strainers) 


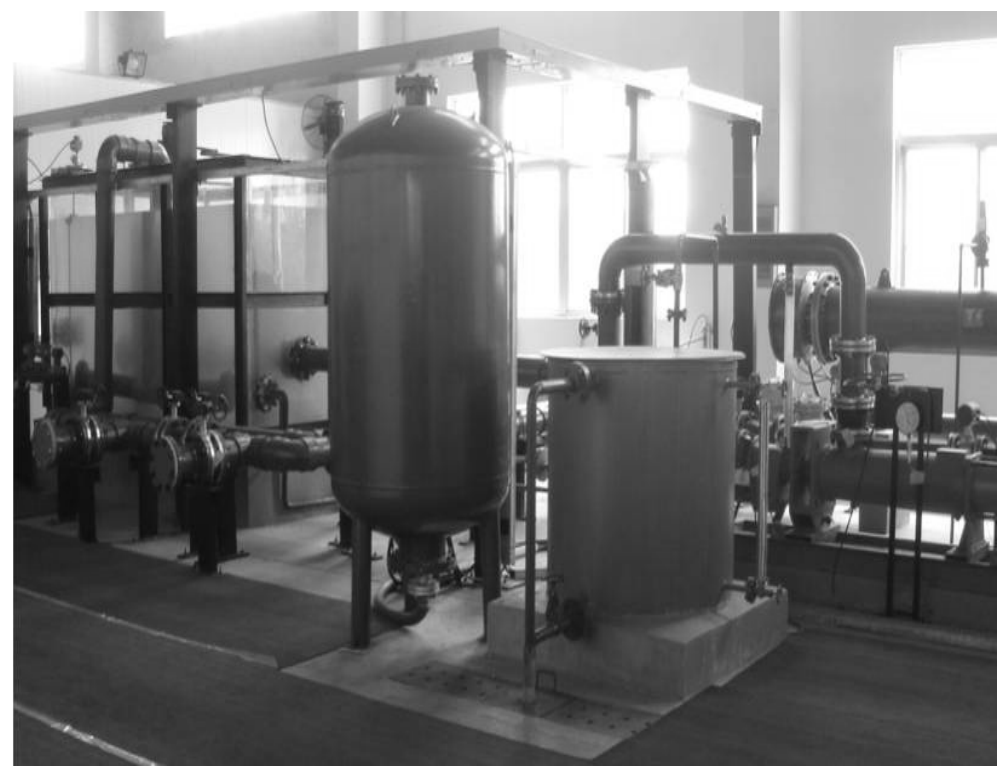

Fig. 6. Photograph 2 of the test system (containment sump strainers)

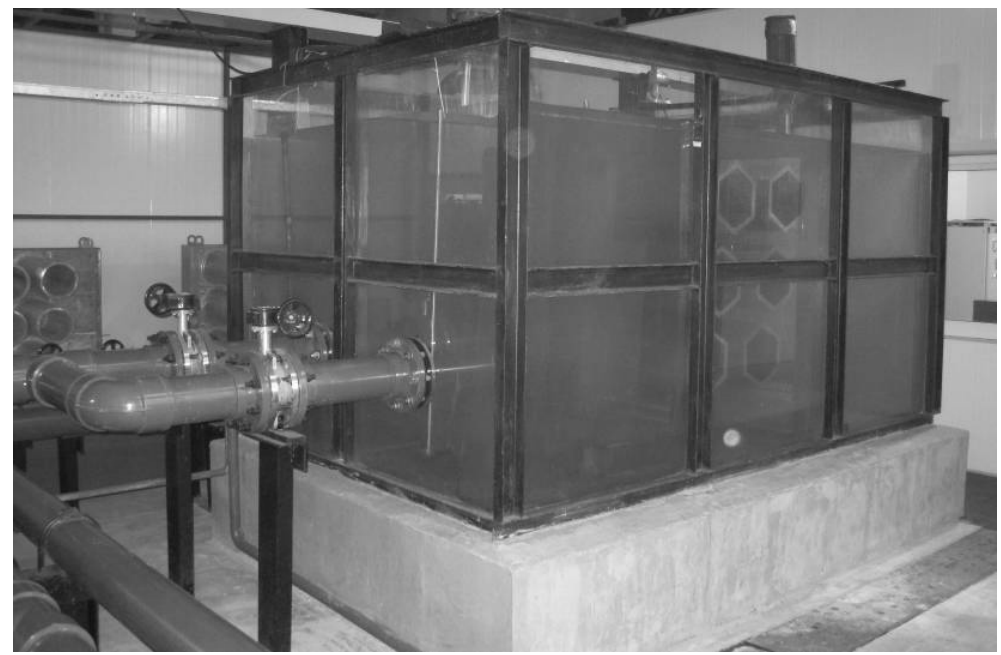

Fig. 7. Photograph 3 of the test system (containment sump strainers)

\subsection{Experiments of control rod drive mechanism}

For the tests of control rod drive mechanism (CRDM) in nuclear power station, the schematic diagram of the experimental apparatus is given in Fig.8. And the photos of the test system are shown in Figs 9 11. 


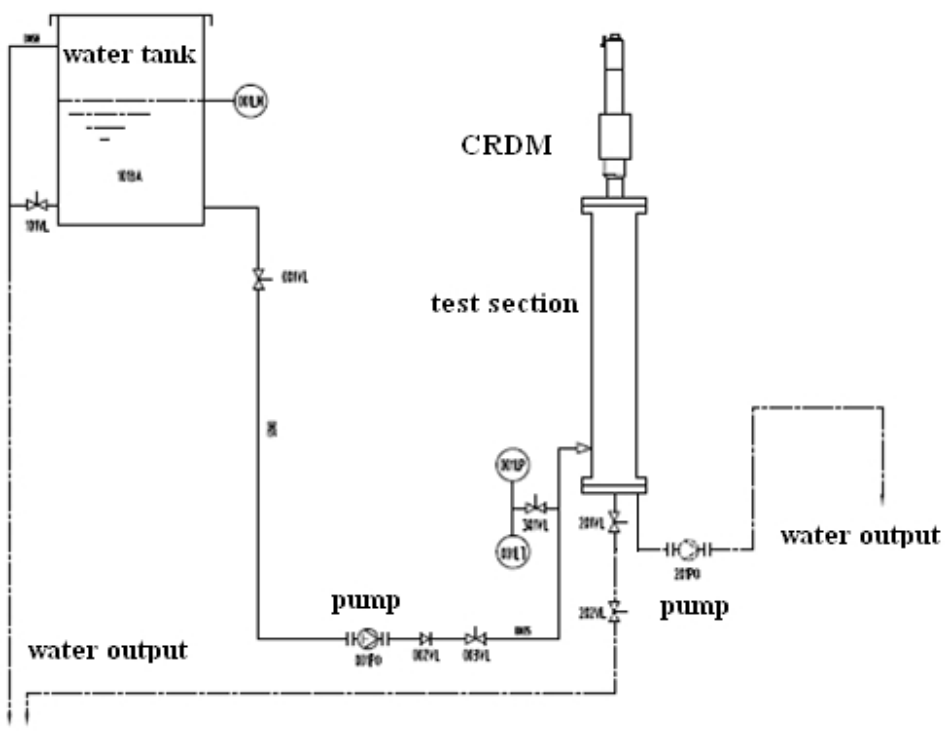

Fig. 8. Schematic Diagram of Experimental Apparatus (CRDM)

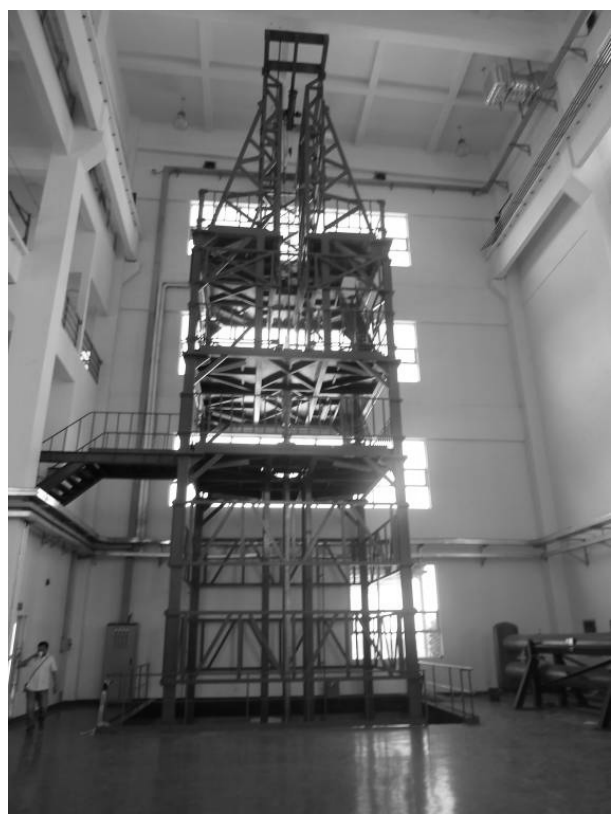

Fig. 9. Photograph 1 of the test system (CRDM)

There are four floors in the test bench, whose site area is $5 \mathrm{~m} \times 5 \mathrm{~m}$ and height is $25 \mathrm{~m}$. The photo of the test bench is shown in Fig. 9. The first floor is used to provide ground support for the test section and to settle the pump and pipeline. The second floor is adopted to upper support for 
the test section. The test section is joined with CRDM by J seal weld on the second floor. The photo of partial test section is shown in Fig. 10 and Fig. 11. CRDM is settled on the third floor. And the fourth floor is used to settle the crane and provide moving space for the driving rod.

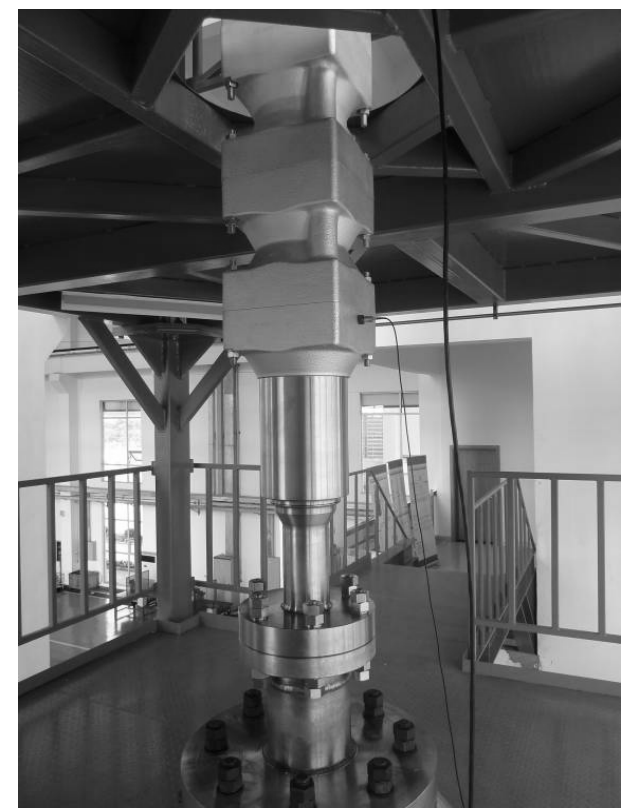

Fig. 10. Photograph 2 of the test system (CRDM)

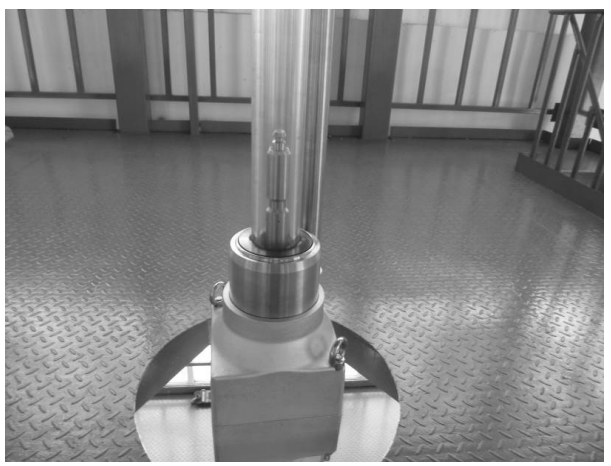

Fig. 11. Photograph 3 of the test system (CRDM)

\section{Results and discussion}

\subsection{Test of tube-bundle channel}

High-speed camera is adopted to carry out experiments of the two-phase boiling flow in the tube-bundle channel for different heat flux and different flow rate. Several representative pictures obtained are displayed in Fig.12. 


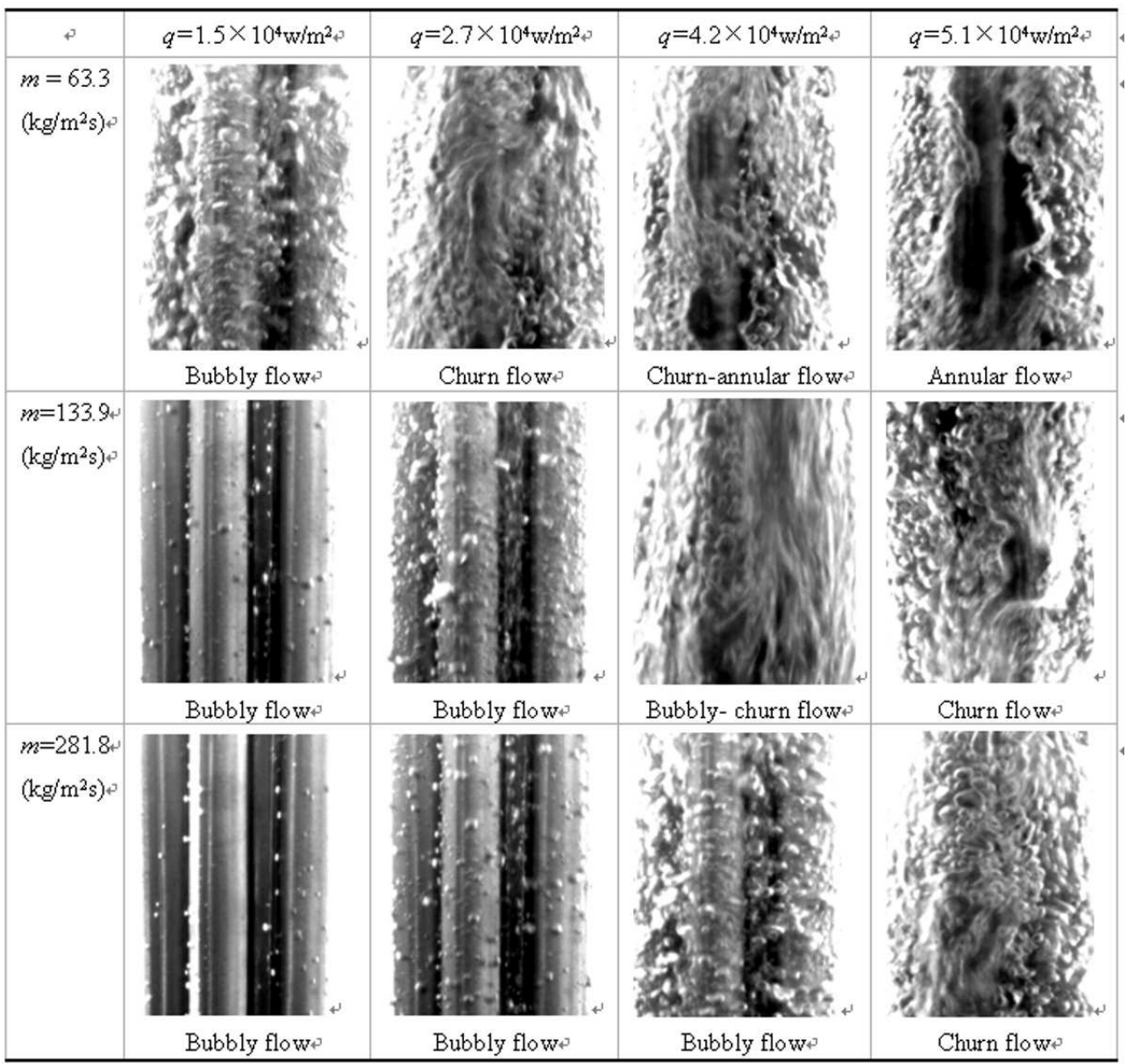

Fig. 12. Flow patterns in a vertical tube-bundle channel

Fig. 12 shows that there are four main flow patterns, bubbly flow, bubbly-churn flow, churn flow and annular flow, which is different from flow patterns of two-phase boiling flow in a circular tube. Through the analyses, it is shown that there may be two reasons for these differences. Firstly, the geometric dimensions cause the different flow patterns. The tubebundle channel is divided into several sub-channels by the tubes, as shown in Fig. 12. And the inner tubes divide the large bubble and make disturbance on two-phase flow. Furthermore, flows in the sub-channels interact and enhance the complexity of two-phase flow in the tube-bundle channel. Secondly, the heating mode of boiling flow in the tubebundle channel and that in the circular tubes are different. When flowing in a circular tube, the fluid is surrounded and heated by the wall of the tube. On the other hand, in a tubebundle channel, the fluid surrounds the tube bundle, which acts as the heating source. Then, all of these might cause differences between flow patterns in vertical tube-bundle channels and that in vertical circular tubes (Hewitt \& Roberts, 1969). 
Two-phase boiling flow in tube-bundle channels exhibits several main flow patterns, bubbly flow, bubbly-churn flow, churn flow and annular flow, as shown in Fig. 13. There are differences from the results gained by Grant \& Chisolm (1979) and Ma (1992). These differences might be caused by the different test conditions. The characteristics of flow patterns and transitions in the present experiments are analyzed as follows.

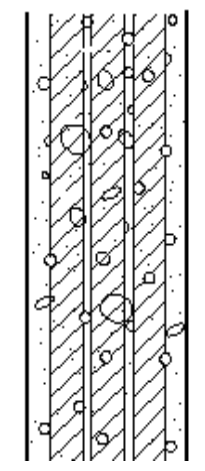

(a) Bubbly flow

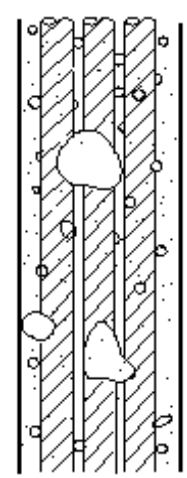

(b) Bubbly- churn flow

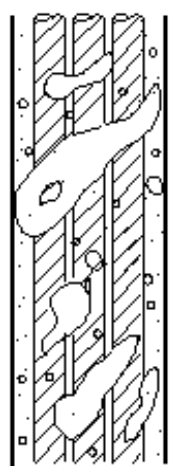

(c) Churn flow

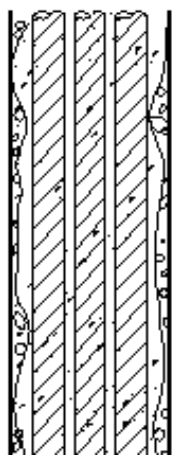

(d) Annular flow

Fig. 13. Schematic diagram of flow pattern in a tube-bundle channel of upward flow

(1) Bubbly flow: In the experiments, bubbles begin to come into being in the liquid when the heat flux is small. The mainstream is liquid and discrete bubbles are dispersed in the mainstream, which indicates that bubbly flow in circular tubes is similar to that in the tubebundle channel, as shown in Fig. 13(a). With the sustaining heating, the dimension and the quantity of bubbles increase gradually along the flow direction, and discrete bubbles begin to aggregate to combine to be large bubbles. Confined by the narrow space in the tubebundle channel, large bubbles transfigure to be oval or crescent.

(2) Bubbly-churn flow: When the little discrete bubbles aggregate and combine to be large bubbles, the tubes agitate and divide these large bubbles. This makes there be no slug flow in the tube-bundle channel. And the flow pattern begins to be transformed from bubbly flow to churn flow.

(3) Churn flow: With the augmentation of heat flux, discrete bubbles continue to aggregate and combine and the aggregation bubbles become bigger in size. These aggregation bubbles present unstable state, on account of the agitation and division of the tubes. And the aggregation bubbles begin to burst into many little discrete bubbles with unequal geometric dimensions. Then, the flow pattern is transformed to churn flow.

When churn flow occurs in the tube-bundle channel, there might be many bubbles with unequal geometric dimensions. The liquid moves up and down in the channel and the twophase flow exhibits surge state.

(4) Annular flow: Heat flux continues increasing, and the dryness fraction in the channel increases too. When the vapor content is higher than that of churn flow, the liquid block is smashed and the vapor unites to be a continuous axle center in the core of the tube-bundle channel. The liquid film goes upward along the wall of PMMA pipe. Thus, annular flow occurs. The liquid film might be broken due to the effect of the vapor wave, as shown in Fig. 4 and Fig. 13 (d). 
In the experiments, there is no mist flow due to the limit of the experiment condition, which is detected by Grant \& Chisolm (1979).

There may be several differences between flow patterns and their transition in circular tubes and that in tube-bundle channels. Firstly, slug flow is one of the main flow patterns for two-phase flow in a circular tube. But the tube-bundle channels, the inner tubes divide the large bubbles and flows in the sub-channels interact, which makes bubbles can not aggregate and combine to be a slug. Thus there is a lack of slug flow in the tube-bundle channel and the flow pattern is transform directly from bubbly flow to churn flow. Secondly, churn flow, as the transition from slug flow to annular flow, exists transitory in circular tubes. Under some circumstances, there might be a lack of churn flow in circular tubes. But in the tube-bundle channel, churn flow presents itself as one of the main flow patterns. And churn flow exists in many experimental conditions and present a long time in the tube-bundle channel, as shown in Fig. 12.

With the same flow rate, there may be different flow patterns in the tube-bundle channel due to the different heat flux. For example, when the flow rate is $281.8\left(\mathrm{~kg} / \mathrm{m}^{2} \mathrm{~s}\right)$, bubbly flow occurs in the tube-bundle channel where the heat flux is comparatively small. But the amount of bubbles begin to increase with the enhanced heat flux. And the flow pattern changes from bubbly flow to churn flow when the heat flux is equal to $5.1 \times 10^{4}\left(w / \mathrm{m}^{2}\right)$. This difference in flow patterns will be more obvious along with the decrease of the flow rate, which is shown in Fig. 12. When the flow rate is $133.9\left(\mathrm{~kg} / \mathrm{m}^{2} \mathrm{~s}\right)$, there will appear three flow patterns, which are bubbly flow, bubbly-churn flow and churn flow, under different heat flux in the tube-bundle channel. And when the flow rate is getting smaller, the flow patterns with differnet heat flux will be differentiated more distinctly. As shown in Fig. 12, there appear four different flow patterns, which are bubbly flow, churn flow, churn-annular flow and annular flow, when the flow rate is equal to $63.3\left(\mathrm{~kg} / \mathrm{m}^{2} \mathrm{~s}\right)$. From above all, it is shown that heat flux will affect the flow pattern more remarkably under the small flow rate condition.

Furthermore, it is found that there may be two different flow patterns in the same crosssection when the experiments run. The flow pattern transitions exhibit unsynchronized in different sub-channels. This unsynchronized phenomenon is caused by the different geometric dimensions, different heat flux and different quantity of discrete bubbles generated in different sub-channels. It was found the same phenomenon in a tube-bundle channel by adopting microprobe to detect the flow pattern transitions (Bergles 1981).

The flow pattern map obtained in the experiments is shown in Fig. 14. Comparisons are made with the results gained by Hewitt \& Roberts (1969), which is figured by dashed line. Two-phase flow patterns and their transition in vertical circular tubes were experimentally studied by Hewitt \& Roberts. The mass flow rate in the present experiments is less than that of Hewitt \& Roberts owing to the experimental condition limits. In Fig. 6, the abscissa $\rho^{\prime} j_{f}^{2}$ and the ordinate $\rho^{\prime \prime} j_{g}^{2}$ are calculated by (Hewitt \& Roberts, 1969),

$$
\begin{gathered}
\rho^{\prime} j_{f}^{2}=\frac{G^{2}(1-x)^{2}}{\rho^{\prime}} \\
\rho^{\prime \prime} j_{g}^{2}=\frac{G^{2} x^{2}}{\rho^{\prime \prime}}
\end{gathered}
$$


It is shown in Fig. 14 that there are great differences between flow pattern transitions in a tube-bundle channel and that in a circular tube. The generation regions of bubbly flow and churn flow in a tube-bundle channel move left in Fig. 14, compared with the region in a circular tube. And it is shown that the regions of bubbly flow and churn flow are larger in a tube-bundle channel, which is caused by that the inner tubes have effects of disturbance and division on the bubbles and these effects make it impossible for discrete bubbles to converge and unite to be a slug. In addition, on account of being heated by the inner tubes, the fluid generates bubbles in the core of the channel, which makes the probability increase for bubbles to converge and unit to be a continuous axle center in the core of the tube-bundle channel, and then the flow pattern transform to annular flow in a tube-bundle channel is earlier than that in a circular tube.

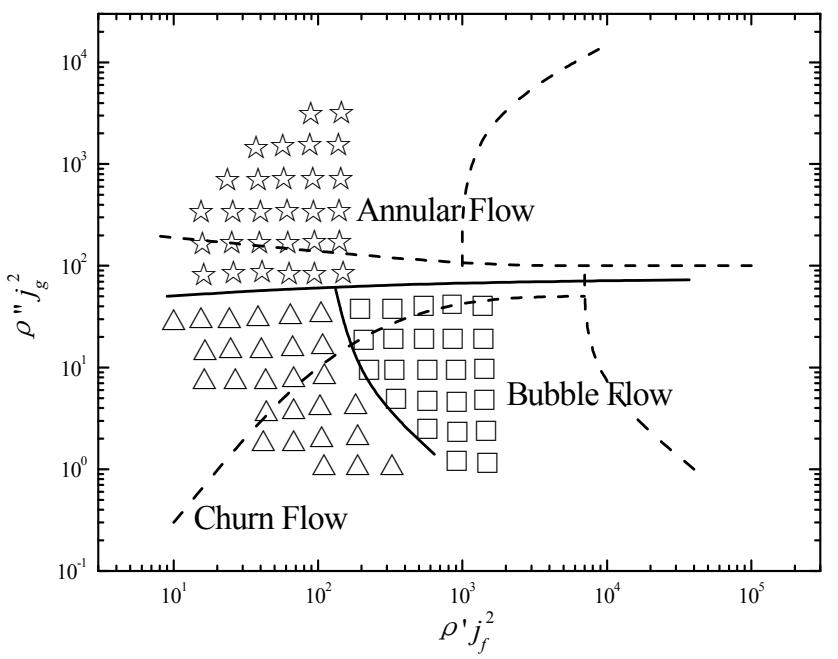

Fig. 14. Flow pattern map of two-phase boiling flow in a tube-bundle channel of upward flow

\subsection{Test of containment sump strainer}

In the tests of containment sump strainer, the solid debris such as fiber and particulate is put into the test system. And then the liquid-solid two-phase flow comes into being. Three main tests are carried out to measure pressure drop of the debris bed, which are clean screen test, thin bed test and full fiber/particulate load test. If there is vortex on the water surface, air may be inhaled into the pump, and then cavitation erosion would appear. So the vortex formation is carefully observed in these tests.

Clean screen test is performed without debris, which is shown in Fig. 15.

The thin bed test is conducted for the purpose of determining the amount of fiber fines which are necessary to completely cover the strainer. When the full coverage of the strainer screen is visually observed, the strainer screen should be photographed. The post-test photograph of thin bed test is shown in Fig. 16. It can be seen that the strainer is completely covered by fibrous debris and the thin bed is formed. 


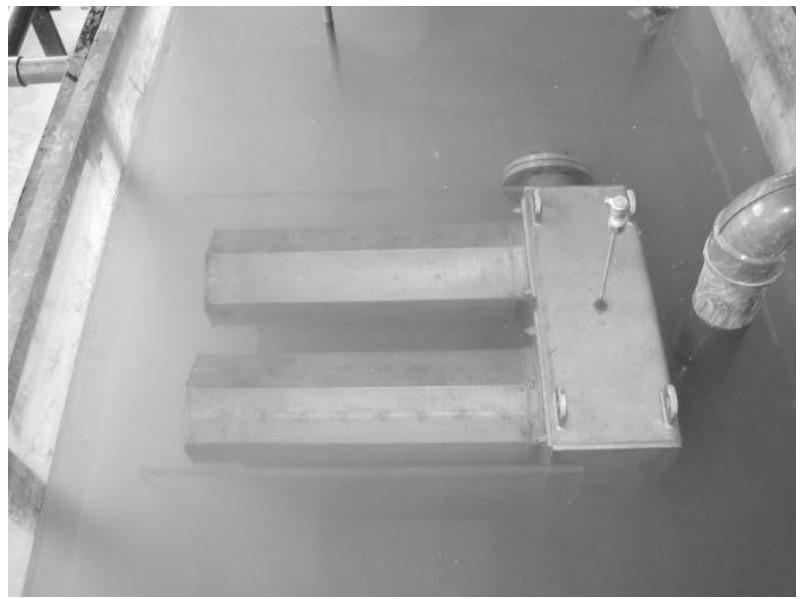

Fig. 15. Photograph of clean screen test

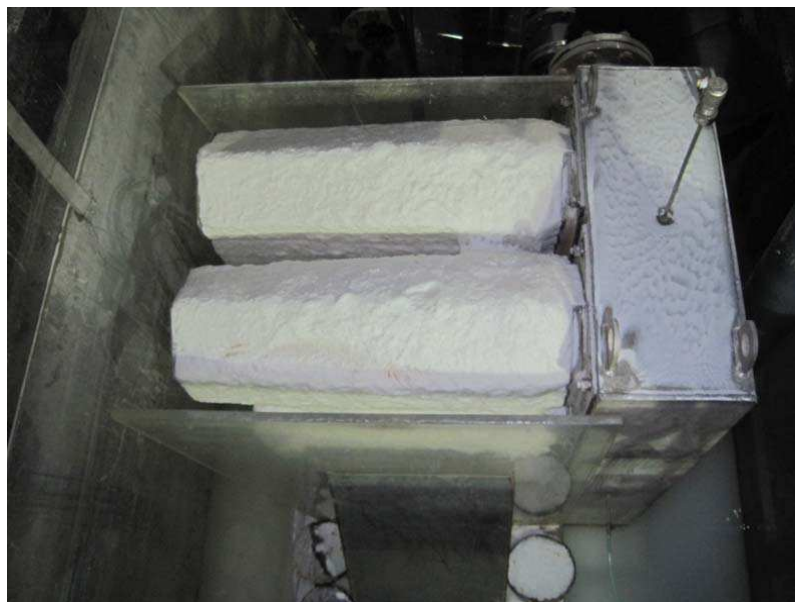

Fig. 16. Post-test photograph of thin bed test

Full fiber/particulate load test is performed to determine the head loss associated with the maximum fibrous and particulate debris load. In this test, full debris load is put into the test tank and the strainer is covered by more debris than that in the thin bed test. And the posttest photograph of full fiber/particulate load test is shown in Fig. 17.

As the safety nuclear apparatus, the containment sump strainers filter the debris out of the recycling water and provide the filtered water for the emergency core cooling system (ECCS) and the containment spray system (CSS). In order to keep the normal operation of ECSS pump and CSS pump, the containment sump strainers must guarantee sufficient NPSH (net positive suction head). Then the pressure loss due to the accident-generated debris accumulated on the sump screens should be one of the most important parameters of he containment sump strainers. And liquid-solid two-phase flow will appear when the accident-generated debris is flushed into the recycling water. NPSH of ECCS pump and CSS 
pump will be directly affected by this two-phase flow, of which the characteristics are important and significant for researchers to investigate.

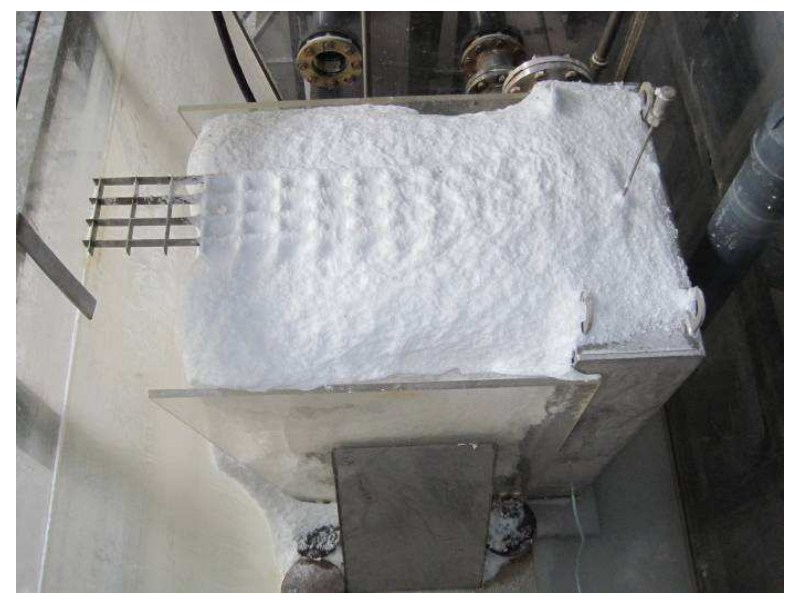

Fig. 17. Post-test photograph of full fiber/particulate load test

In the tests of containment sump strainer, the solid debris such as fiber and particulate is put into the liquid. And the liquid-solid two-phase flow comes into being, which is different from the flow patterns in tube-bundle channels. The liquid-solid two-phase flow and the debris bed covering on the containment sump strainer are carefully observed and recorded in the tests.

In the recycling course, the ECCS and CSS systems would adopt the water in the containment as pump source when the water in PTR001BA was used up. The debris generated by LOCA or HELB would be transported to the containment ground floor with the elevation of $-3.5 \mathrm{~m}$. And a fraction of debris would accumulate on the sump screen which could induce pressure loss and might lead to the pump failure of ECCS and CSS systems. The debris transportation fraction to the sump strainers is analyzed by numerical simulation.

The authors take Daya Bay PWR for example to establish a 3-D computational model, with the purpose of studying the debris types and contents transported to the sump strainers. According to the actual dimension of the containment sump strainer in Daya Bay nuclear power station, a 3-D CAD model is established, as shown in Fig. 18. The altitude of the CAD model is ranging from $-3.5 \mathrm{~m}$ to $0 \mathrm{~m}$.

Then this CAD model is imported into Gambit, and the computational grid can be plotted. The cooper mode is adopted in defining the computational grid. In the complex locality and the key position, the computational grid is refined to resolve the important features. For the main part of the model, $5 \times 5 \times 5 \mathrm{~cm}$ mesh spacing is induced in $\mathrm{x}-\mathrm{y}-\mathrm{z}$ directions. And the total cell amount in the model is 7,166,332, which is shown in Fig. 19.

In CFD model, the water temperature in the containment is set as $120^{\circ} \mathrm{C}$ and the pressure is 1.99 bar. In this circumstance, the water is sub-cooled and the water density is $943 \mathrm{~kg} / \mathrm{m}^{3}$, and the viscosity is $2.32 \times 10^{-4} \mathrm{~Pa} \cdot \mathrm{s}$.

According to the mass conservation principle and momentum conservation principle, continuity equation and momentum equation are established. 


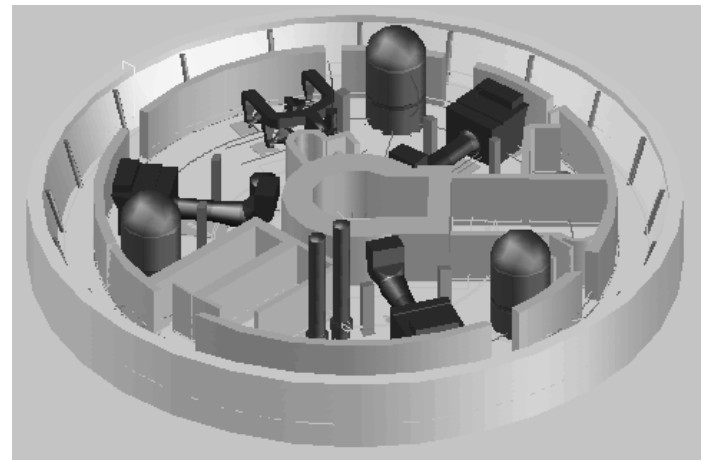

Fig. 18. 3-D CAD model of containment

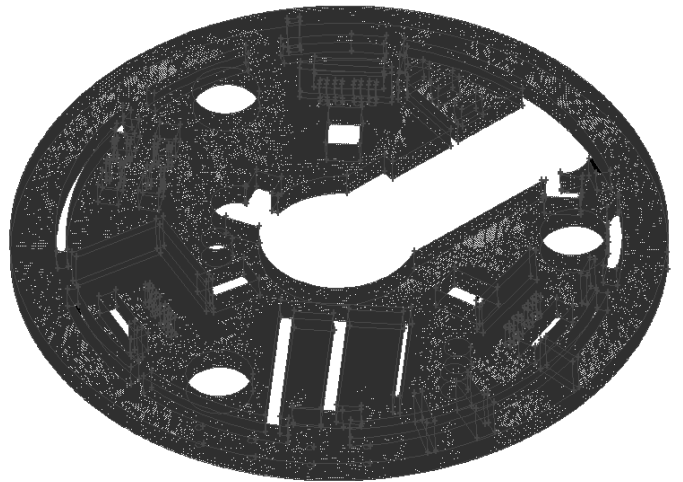

Fig. 19. Computational grid of containment

$$
\begin{gathered}
\frac{\partial}{\partial t} \rho+\frac{\partial}{\partial x_{i}}\left(\rho u_{i}\right)=0 \\
\frac{\partial}{\partial t}\left(\rho u_{i}\right)+\frac{\partial}{\partial x_{j}}\left(\rho u_{i} u_{j}\right)=-\frac{\partial p}{\partial x_{i}}+\frac{\partial}{\partial x_{j}}\left(\mu \frac{\partial u_{i}}{\partial x_{j}}\right)+S_{i}
\end{gathered}
$$

Where, $\rho$ is the liquid density, $\mathrm{kg} / \mathrm{m}^{3} . u$ is the flow velocity, $\mathrm{m} / \mathrm{s} . t$ is time, $\mathrm{s} . \mu$ is the dynamic viscosity Pa s. $S$ is the source term.

In the CFD calculation, the general transportation equations are established with the use of $k-\varepsilon$ technique.

$$
\begin{gathered}
\frac{\partial}{\partial t}(\rho k)+\frac{\partial}{\partial x_{i}}\left(\rho k u_{i}\right)=\frac{\partial}{\partial x_{j}}\left[\left(\mu+\frac{\mu_{t}}{\sigma_{k}}\right) \frac{\partial k}{\partial x_{j}}\right]+G_{k}-\rho \varepsilon+S_{k} \\
\frac{\partial}{\partial t}(\rho \varepsilon)+\frac{\partial}{\partial x_{i}}\left(\rho \varepsilon u_{i}\right)=\frac{\partial}{\partial x_{j}}\left[\left(\mu+\frac{\mu_{t}}{\sigma_{\varepsilon}}\right) \frac{\partial \varepsilon}{\partial x_{j}}\right]+C_{1 \varepsilon} \frac{\varepsilon}{k} G_{k}-C_{2 \varepsilon} \rho \frac{\varepsilon^{2}}{k}+S_{\varepsilon}
\end{gathered}
$$




$$
\begin{gathered}
\mu_{t}=\rho C_{\mu} \frac{k^{2}}{\varepsilon} \\
G_{k}=\mu_{t}\left(\frac{\partial u_{i}}{\partial x_{j}}+\frac{\partial u_{j}}{\partial x_{i}}\right) \frac{\partial u_{i}}{\partial x_{j}}
\end{gathered}
$$

Where, $\mu_{t}$ is the turbulent viscosity coefficient. $G_{k}$ is the turbulent energy generated by timeaverage velocity gradient. $\sigma_{k}$ and $\sigma_{\varepsilon}$ are turbulent Prandtl number of $k$ equation and $\varepsilon$ equation.

The velocity field of water flow in the containment is shown in Fig. 20. The water would tumble the sunken debris along the ground floor or lift debris over a curb in the area where the water velocity is high enough.
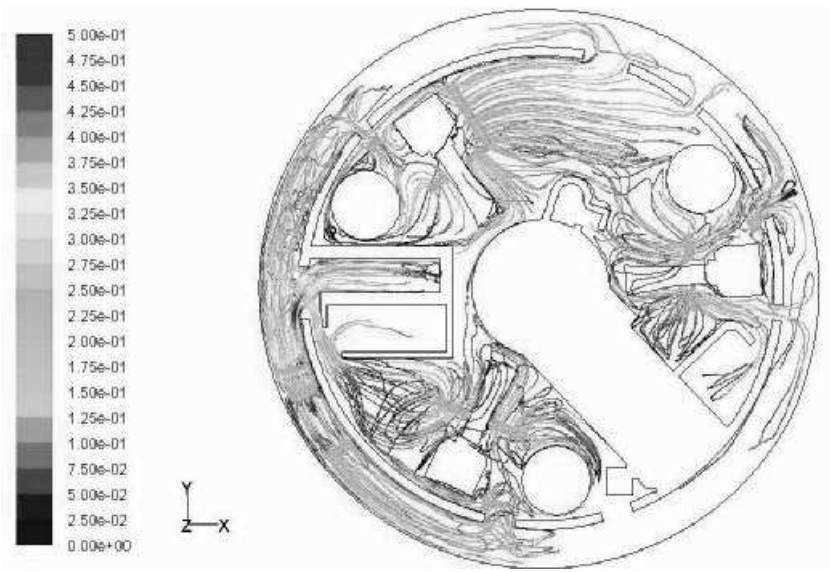

Fig. 20. Velocity field in containment

The experimental and numerical results gained above can provide necessary basis for the analysis of the properties of containment sump strainer and for the design of new-type containment sump strainers.

\subsection{Test of control rod drive mechanism}

In the beginning tests of control rod drive mechanism (CRDM), two phase flow would come into being because there is air dissolved in the liquid and hidden in the groove of driving rod. The air would be decomposed from the water and be extruded out of the groove when there is disturbance. For example, electrifying of coil component, up-down movement of driving rod, swing in and out of gripper component would give rise to disturbance and make the bubbles appear in the liquid. There is small amount of air dissolved or hidden in the water and twophase flow would not occur in the test after CRDM moves several days.

In the tests, there is no bubble observed and the air would not be decomposed from the water when there is no disturbance, which is shown in Fig. 21(a). There are three coil components in CRDM, which are lifting coil, moving coil and stationary coil. And bubbles begin to come into being and there appear several separate bubbles when the coil component is electrifying and the gripper swings into the driving rod, which is shown in 


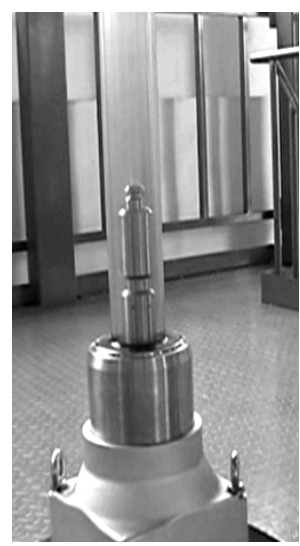

(a)

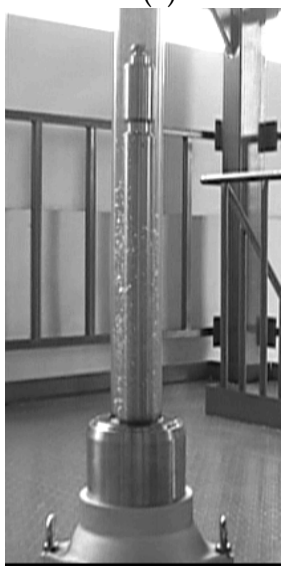

(d)

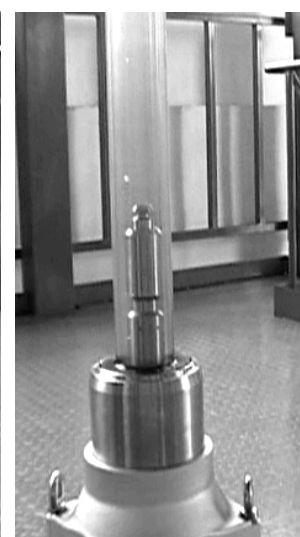

(b)

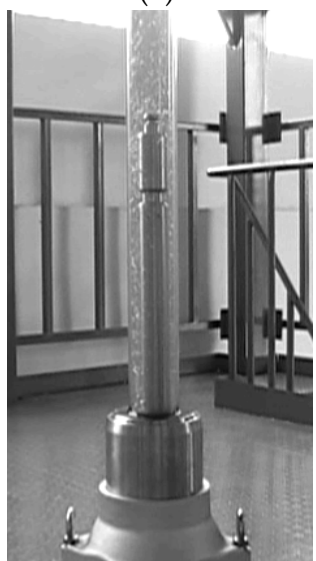

(e)

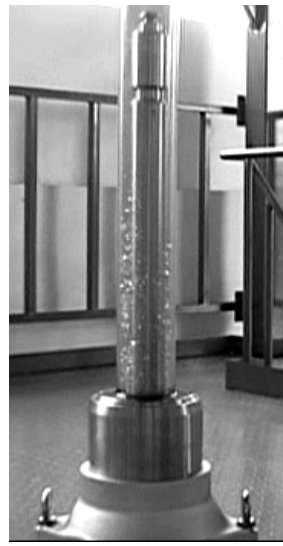

(c)

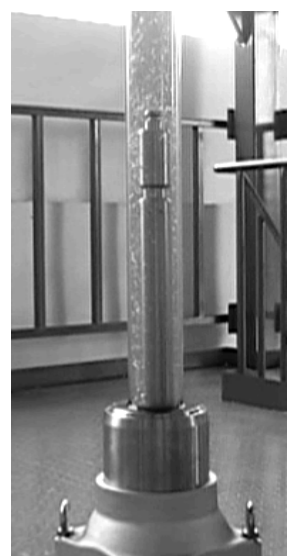

(f)

Fig. 21. Rod lifting tests

Fig. 21(b). In the tests of rod lifting, the driving rod goes upwards, the electromagnet is engaged and grippers swing into and out of the driving rod one by one. At this time, large numbers of bubbles appear in the liquid and bubbly flow come into being, as shown in figures 21 (c) $\sim(\mathrm{f})$. In the tests of rod inserting, the phenomenon of downwards movement of the driving rod is similar to that of upwards movement.

In the tests of rod dropping, the power of three coils is cut off, the grippers swing out of the driving rod, and the driving rod free falls in the rod travelling house. In this process, the disturbance is transitory and bubbles appear in the liquid, of which the amount is less than that of rod lifting. When the bubbles go up to the bottom of the test section and there is no disturbance again, no bubbles will generate in the liquid, as shown in Fig. 22.

In the cold tests of rod lifting, rod inserting and rod dropping, only bubbly flow comes into being due to that the amount of gas dissolved in the liquid is small. After CRDM moves several days, the gas dissolved are all driven out of the liquid and there will not appear twophase flow. 


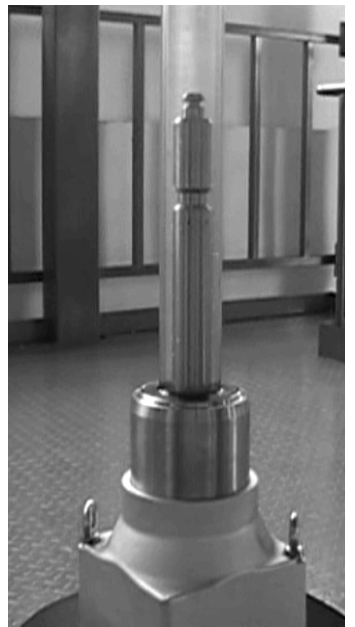

(a)

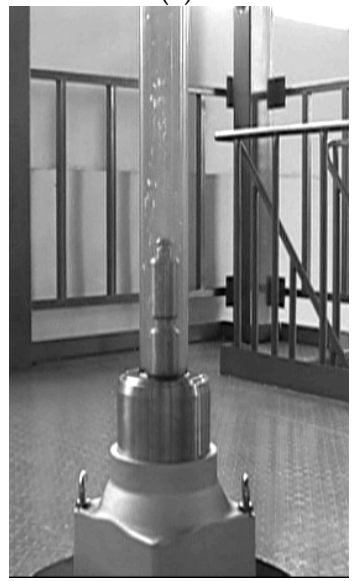

(c)

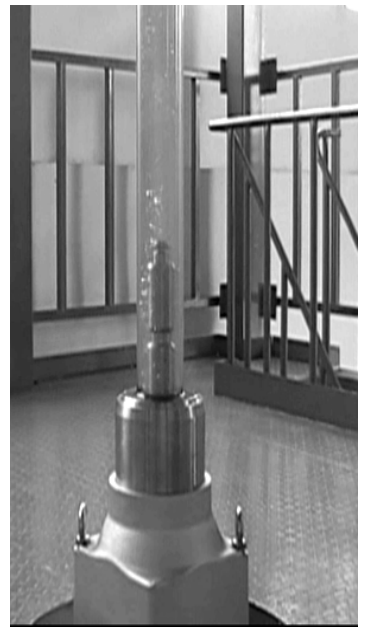

(b)

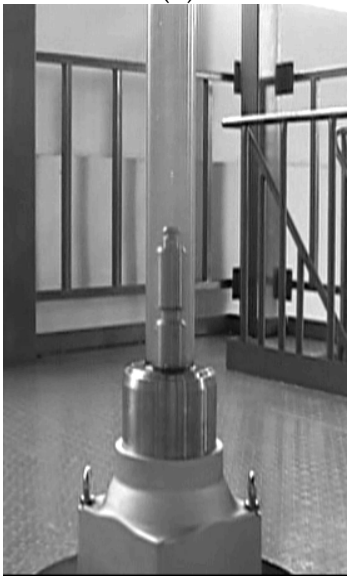

(d)

Fig. 22. Rod dropping tests

\section{Conclusion}

On the basis of the experimental results, the conclusions are obtained,

(1) It is found that there are several main flow patterns, bubbly flow, bubbly-churn flow, churn flow and annular flow in the tube-bundle channel. And there are great differences between flow patterns and their transitions in a tube-bundle channel and that in a circular tube.

(2) Experiments show that there may be two different flow patterns in the same crosssection of the tube-bundle channel. And the flow pattern transitions exhibit unsynchronized in different sub-channels. This unsynchronized phenomenon is caused by the different geometric dimensions, different heat flux and different quantity of discrete bubbles generated in different sub-channels. 
(3) The flow pattern map is drawn on the basis of experiments. Comparisons are conducted between flow pattern transition in a tube-bundle channel and that gained by Hewitt \& Roberts. The results show that the regions of bubbly flow and churn flow in a tube-bundle channel are larger than that in a circular tube. In addition, the flow pattern transforming to annular flow is earlier in a tube-bundle channel than that in a circular tube.

(4) Three main tests are carried out to measure pressure drop of the containment sump strainers. The photographs are taken and the vortex is not observed in these tests.

(5) In the tests of control rod drive mechanism, two-phase flow is observed. The results of upwards movement and drop movement of the driving rod are compared and analyzed.

\section{Acknowledgments}

The authors would like to acknowledge the financial support from the National Science and Technology Program of China (Grant No. 2011BAA06B00). The authors would also like to thank Messrs. Yu Jiang., Zhou Jianming, Wu Wei, Bai Bing, Lu Zhaohui for the helpful discussions.

\section{References}

Bergles, A. E. (1981). Two-phase flow and heat transfer in the power and process industries. ISBN: 978-0070049024, McGraw-Hill Inc., Washington, US

Chan A. M. C. \& Shroukri M. (1987). Boiling characteristics of small multi-tube bundles. Journal of Heat Transfer. Vol.109, pp.753-760. ISSN 0022-1481, New York, USA

Grant I. D. R. \& Chisolm D. (1979). Two-phase flow on the shell-side of a segmentally baffled shell and tube heat exchanger. Journal of Heat Transfer. Vol.101, pp.38-42, ISSN: 0022-1481

Hewitt, G. F. \& Roberts, D. N. (1969). Studies of two-phase flow patterns by simultaneous X-ray and flash photography, Atomic Energy Research Establishment, ISSN: 0029-5450, Harwell, England

Lu, G. Y.; Ren, J. S.; Zhang, C. G. \& Lin, P. (2011). Debris transport calculation of nuclear power plant containment, 19th International Conference On Nuclear Engineering, ISBN: 978-0-7918-4351-2, Osaka, Japan, October 24 - 25, 2011

Lu, G. Y.; Ren, J. S.; Zhang, C. G. \& Lin, P. (2011). Investigation on pressure drop characteristics and disposal optimization of conflux channels of containment sump strainers, 19th International Conference On Nuclear Engineering, ISBN: 978-0-79184351-2, Osaka, Japan, October 24 - 25, 2011

Lu, G. Y.; Ren, J. S.; Zhang, C. G. \& Xiang, W. Y. (2011). Application and development of containment sump strainers in PWR power stations in China, 19th International Conference On Nuclear Engineering, ISBN: 978-0-7918-4351-2, Osaka, Japan, October $24-25,2011$

Ma Weimin. (1992). Experimental investigations on two-phase flow in heat exchangers. $\mathrm{Xi}^{\prime}$ an Jiaotong University, ISSN: 1671-8267

Petigrew, M. J. \& Taylor C. E. (1994).Two-phase flow-induced vibration. Journal of Pressure Vessel Technology, Vol.166, pp. 233-253, ISSN: 0094-9930

Sadatomi, M. \& Kawahara, A. (2004). Flow characteristics in hydraulically equilibrium twophase flows in a vertical $2 \times 3$ rod bundle channel. International Journal of Multiphase Flow, Vol.30, pp.1093-1119, ISSN: 0301-9322 


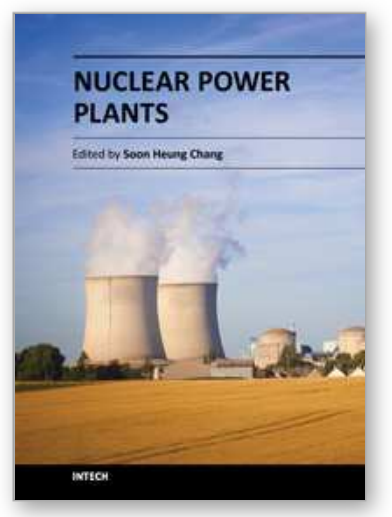

\author{
Nuclear Power Plants \\ Edited by Dr. Soon Heung Chang
}

ISBN 978-953-51-0408-7

Hard cover, 340 pages

Publisher InTech

Published online 21, March, 2012

Published in print edition March, 2012

This book covers various topics, from thermal-hydraulic analysis to the safety analysis of nuclear power plant. It does not focus only on current power plant issues. Instead, it aims to address the challenging ideas that can be implemented in and used for the development of future nuclear power plants. This book will take the readers into the world of innovative research and development of future plants. Find your interests inside this book!

\title{
How to reference
}

In order to correctly reference this scholarly work, feel free to copy and paste the following:

Lu Guangyao, Ren Junsheng, Huang Wenyou, Xiang Wenyuan, Zhang Chengang and Lv Yonghong (2012). Investigation on Two-Phase Flow Characteristics in Nuclear Power Equipment, Nuclear Power Plants, Dr. Soon Heung Chang (Ed.), ISBN: 978-953-51-0408-7, InTech, Available from:

http://www.intechopen.com/books/nuclear-power-plants/investigation-on-two-phase-flow-characteristics-innuclear-power-equipment

\section{INTECH}

open science | open minds

\section{InTech Europe}

University Campus STeP Ri

Slavka Krautzeka 83/A

51000 Rijeka, Croatia

Phone: +385 (51) 770447

Fax: +385 (51) 686166

www.intechopen.com

\section{InTech China}

Unit 405, Office Block, Hotel Equatorial Shanghai

No.65, Yan An Road (West), Shanghai, 200040, China

中国上海市延安西路65号上海国际贵都大饭店办公楼405单元

Phone: +86-21-62489820

Fax: +86-21-62489821 
(C) 2012 The Author(s). Licensee IntechOpen. This is an open access article distributed under the terms of the Creative Commons Attribution 3.0 License, which permits unrestricted use, distribution, and reproduction in any medium, provided the original work is properly cited. 